\title{
Addressing mental health disorders and HIV vulnerability of marginalized adolescents in Addis Ababa, Ethiopia
}

\author{
Nrupa Jani \\ Population Council \\ Lung Vu \\ Population Council \\ Sam Kalibala \\ Population Council \\ Gebeyehu Mekonnen
}

Kay Lynn

Follow this and additional works at: https://knowledgecommons.popcouncil.org/departments_sbsr-hiv

Part of the Demography, Population, and Ecology Commons, Family, Life Course, and Society Commons, International Public Health Commons, and the Mental and Social Health Commons How does access to this work benefit you? Let us know!

\section{Recommended Citation}

Jani, Nrupa, Lung Vu, Sam Kalibala, Gebeyehu Mekonnen, and Kay Lynn. 2015. "Addressing mental health disorders and HIV vulnerability of marginalized adolescents in Addis Ababa, Ethiopia," HIVCore Final Report. Washington, DC: USAID I Project Search: HIVCore. 


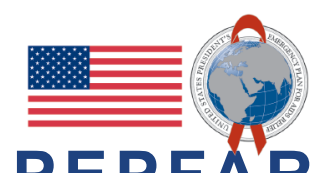

(:) USAID/Project SEARCH

HIVCore

\section{ADDRESSING MENTAL}

HEALTH DISORDERS AND

HIVVULNERABILITY OF

MARGINALIZED ADOLESCENTS

IN ADDIS ABABA, ETHIOPIA

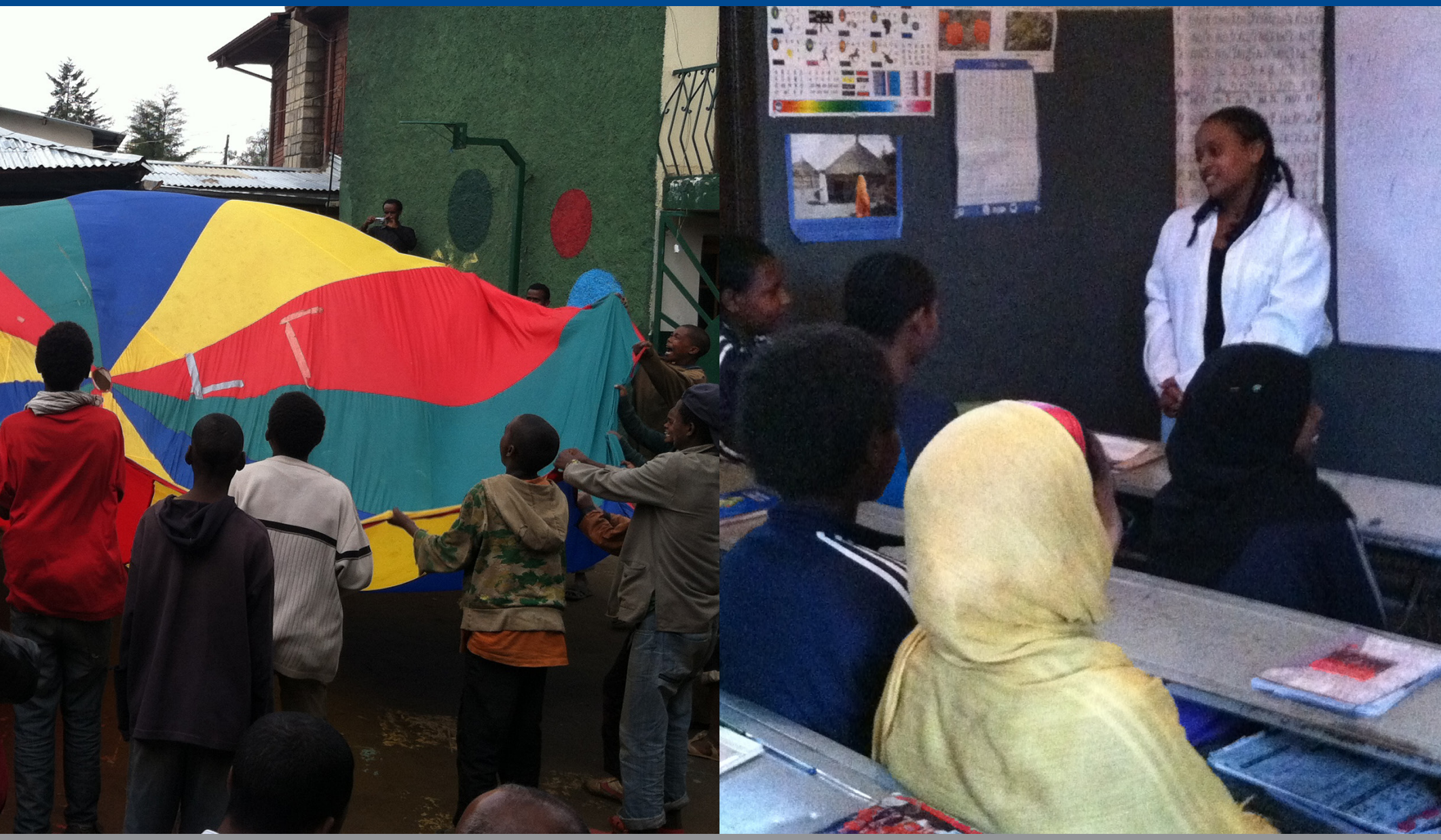

18 December 2015

This publication was produced for the United States Agency for International Development. It was prepared by Nrupa Jani, Lung Vu, Sam Kalibala, Gebeyehu Mekonnen, and Lynn Kay. 



\section{ADDRESSING MENTAL HEALTH DISORDERS AND HIV VULNERABILITY OF MARGINALIZED ADOLESCENTS IN ADDIS ABABA, ETHIOPIA}

NRUPA JANI, LUNG VU, SAM KALIBALA, GEBEYEHU MEKONNEN, AND LYNN KAY

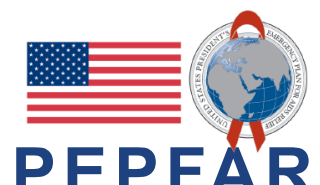




\section{ACKNOWLEDGMENTS}

We would like to first and foremost thank all the Biruh Tesfa and Retrak participants of this study. This study would not have been possible without the Population Council-Addis research team, including Annabel Erulkar, Habtamu Demele, Lemi Negeri, Tigest Tamrat, and Selamawit Gidey, as well as Meredith Sheehy (formerly Population Council-New York), and Nanlesta Pilgrim (Population CouncilWashington, D.C.). We greatly appreciate the work of our Retrak colleague Julyata Shibru, as well as our psychometrician, Kassahun Habtamu, who assisted with both the design and implementation of the study, and lead study psychologist Lake Bedilu. We are also grateful to all the Biruh Tesfa mentors and Zelalem Belay for their assistance in implementing the study and coordinating the data collection efforts, all of the counselors, counselor supervisors, and clinical nurses, as well as the government of Ethiopia, and the community members at large who support the implementation of both these programs. Our special thanks also go to our USAID Mission colleagues including Tsegaye Tilahun and Renee Demarco, and the HIVCore management team at USAID/Washington, Sarah Sandison and Glenn Post, for their leadership. Lastly, HIVCore would like to acknowledge the reviewers who provided detailed technical input that substantially improved this report: Irit Sinai (HIVCore/Palladium) and Annabel Erulkar (Population Council).

We would also like to thank Sherry Hutchinson, HIVCore's Knowledge Management Specialist, for coordinating reviewer comments and author responses throughout the various drafts of this report.
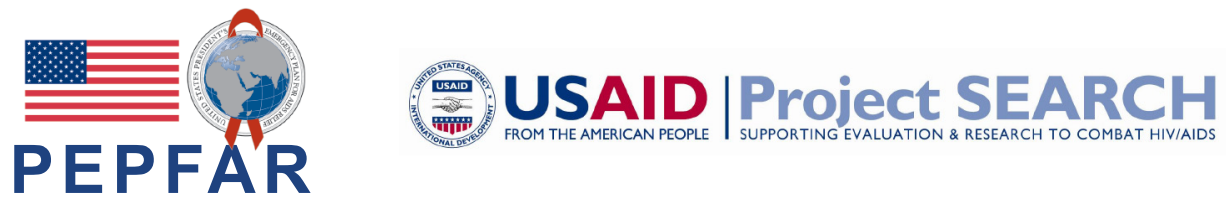

This report was made possible through support provided by the President's Emergency Plan for AIDS Relief and the U.S. Agency for International Development (USAID) via HIVCore, a Task Order funded by USAID under the Project SEARCH indefinite quantity contract (Contract No. AID-OAA-TO-11-00060).

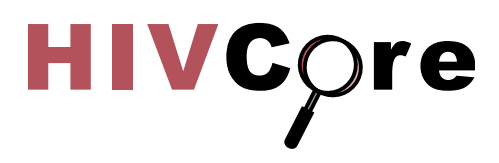

HIVCore improves the efficiency, effectiveness, scale, and quality of HIV treatment, care, and support, and prevention of mother-to-child transmission (PMTCT) programs. The Task Order is led by the Population Council in partnership with Elizabeth Glaser Pediatric AIDS Foundation, Palladium (formerly Futures Group), and the University of Washington.

Published in December 2015. (C) 2015. The Population Council Inc.

Suggested citation: Jani, Nrupa, Lung Vu, Sam Kalibala, Gebeyehu Mekonnen, and Lynn Kay. 2015. “Addressing mental health disorders and HIV vulnerability of marginalized adolescents in Addis Ababa, Ethiopia," HIVCore Final Report.

Washington, DC: USAID | Project Search: HIVCore. 



\section{ACRONYMS}

ASEBA

EDHS

DHS

FHAPCO

GEE

HIV

LTFU

$\mathrm{MOH}$

MDD

NGO

PSS

SRH

USAID

YSR
Achenbach System of Empirically Based Assessment

Ethiopian Demographic and Health Survey

Demographic and Health Survey

Federal HIV/AIDS Prevention and Control Office

General Estimating Equation

Human Immunodeficiency Virus

Loss to Follow-up

Ministry of Health

Music, Drama, and Dance

Nongovernmental Organization

Peer Support Services

Sexual and Reproductive Health

United States Agency for International Development

Youth Self-report 


\section{EXECUTIVE SUMMARY}

Ethiopia is experiencing an increasingly urban, female-centered HIV epidemic alongside a rise in rural migration of adolescents to Addis Ababa. Often these migrants are confronted by social challenges such as lack of education, inadequate housing, unstable employment conditions, and physical and sexual abuse. These difficult living circumstances contribute to psychological and mental health problems among these vulnerable adolescents, potentially putting them at greater risk of acquiring HIV. However, knowledge about how targeted mental health interventions can impact HIV-related outcomes worldwide, and in Ethiopia, remains limited.

\section{OBJECTIVES}

The goal of this study was to pilot test a strategy for addressing mental health problems, such as stress, anxiety, depression, and emotional and behavioral issues, as well as measure if the provision of a tailormade psychosocial support intervention can affect HIV-related outcomes among vulnerable migrant adolescents in Addis Ababa, Ethiopia.

The specific objectives of this study were to pilot test a targeted psychosocial support counseling intervention and document any changes in :1) psychological and mental health problems of the target population; and 2) responsiveness to HIV programming and services among the target population.

\section{METHODS}

\section{Study design}

This was a before and after intervention study comprising a cohort of migrant male and female adolescents aged 15 to 18 years old in Addis Ababa, Ethiopia receiving services from two service delivery organizations-Biruh Tesfa and Retrak. Biruh Tesfa works with migrant young women who are predominantly employed as domestic workers, while Retrak works with young men in Addis Ababa who are often engaged in street labor activities. Participants were screened using the Youth Self-report (YSR) tool and a behavioral survey at baseline, then delivered a three-month psychosocial counseling pilot intervention. The intervention was followed by an endline YSR and behavioral survey. Due to ethical concerns, participants with severe mental health issues at baseline $(\mathrm{N}=24)$ were referred to clinical services for appropriate treatment and follow-up care, and thus excluded from the study.

\section{Description of the intervention}

The study intervention consisted of the delivery of a client-driven, psychosocial counseling intervention, administered by trained counselors, which discussed adolescent development, psychological wellbeing, mental health problems, and factors increasing vulnerability of marginalized adolescents. Study counselors administered the targeted counseling intervention, which included both individual and group counseling sessions, such as creative art therapies and music, drama, and dance (MDD), to all consenting enrolled participants from the two Addis Ababa-based service delivery organizations of Biruh Tesfa and Retrak. 
These counseling sessions also covered topics of sexual health and HIV/AIDS (risk behavior, knowledge, and prevention strategies, including HIV testing and counseling), alcohol and drug abuse, and experience with violence, as appropriate, with each participant. This intervention was designed based on findings from a formative study conducted among the same study population.

\section{Data analysis}

Changes of key outcome indicators between baseline and endline were examined using the data of 315 female participants and 102 male participants who completed both baseline and endline surveys. Key outcomes included four mental health indicators (depression, anxiety problem, social problem, and aggressive behavior), and HIV-related factors (sexual risk, knowledge of HIV, HIV testing and counseling, and seeking sexual health services). Because all key indicators are binary, the McNemar test was used to assess changes in outcomes of same individuals between baseline and endline. We also used generalized estimating equation (GEE) to assess the association between mental health and the changes in mental health status, and HIV-related outcomes over time.

\section{KEY FINDINGS}

\section{Sample characteristics}

- The majority of male respondents migrated to Addis Ababa from a rural village (37.4 percent), or from a small town (36.1 percent). Over half (55.7 percent) had attained $1-5$ years of schooling; 39.0 percent had temporary employment, 37.9 percent were self-employed, and 15.8 percent were unemployed; none had full-time or permanent employment. The majority of male participants (71.8 percent) had at least one of the four mental-health/psychosocial problems (social problem, attention problem, anxiety problem, or aggressive behavior).

- About two-thirds of the female respondents migrated to Addis Ababa from a rural area, a majority of them (64.4 percent) were permanently employed, 54.0 percent had achieved $1-5$ years of schooling, and one-third (37.3 percent) had at least one of the four mental health/psychosocial problems listed above.

\section{Observed changes post-intervention}

- Female participants experienced significant reductions in two of the four key mental health indicators. In particular, at baseline, 8.6 percent of young women presented with attention problems, while at endline this proportion reduced to 4.8 percent $(\mathrm{p}<.05)$. Similarly the prevalence of aggressive behavior also decreased from 24.4 percent to 13.0 percent $(\mathrm{p}<.01)$, resulting in an overall decrease of the prevalence of any mental health problems from 34.9 percent to 15.1 percent $(\mathrm{p}<.01)$. No statistically significant baseline to endline reductions were seen in mental health outcomes among young men.

- Female participants experienced significant increases in comprehensive HIV knowledge from baseline to endline (16.8 percent to 24.4 percent; $\mathrm{p}<.05)$. Additionally, female participants experienced significant increases in knowledge of a place to get tested for HIV (68.5 percent baseline to 77.2 percent endline $(\mathrm{p}<.01))$, and in ever being tested for HIV $(29.8$ percent baseline to 36.1 percent endline $(\mathrm{p}<.01)$ ). Male participants also demonstrated a significant increase in HIV knowledge from 20.6 percent at baseline to 34.3 percent at endline $(\mathrm{p}<.05)$. In addition, young men increased their knowledge of a place to test for HIV, from 88.2 percent at baseline to 95.1 percent at endline $(\mathrm{p}<.05)$, 
and ever having tested for HIV, 45.1 percent to 69.6 percent $(\mathrm{p}<.01)$. Additionally, young men's use of sexual and reproductive health (SRH) services, such as testing for HIV, also significantly increased from 31.4 percent at baseline to 54.9 percent at endline $(\mathrm{p}<.01)$ as well as their reporting of discussing $\mathrm{SRH}$ issues with anyone in the last three months (51.1 percent baseline and 71.6 percent endline; $\mathrm{p}<$ $.01)$.

- We also investigated the association between having any of the four mental health issues (depression, anxiety, social problem, or aggressive behavior) and HIV-related outcomes, and how improvement in mental health might affect changes in HIV-related outcomes. We found that among female participants, those with any mental health issue were less likely to report comprehensive HIV knowledge $\mathrm{OR}=0.2$ (95\%CI: $0.05-0.89)$ or perceived HIV risk OR $=0.2$ (95\% CI: 0.03-0.68). For male participants, no significant associations were found between mental health status and HIV-related outcomes.

\section{RECOMMENDATIONS}

- After administering the targeted, three-month intervention we observed that mental health problems for vulnerable female adolescents reduced and HIV-related indicators for both vulnerable male and female adolescents improved. However we cannot attribute these changes to our study intervention since we did not have a control group; thus future studies may benefit from a more robust study design (i.e., experimental).

- Our study was restricted to a three-month pilot due to resource limitations. Future studies may benefit from a longer intervention period in order to see greater impact, especially among males. A longer intervention period could also allow for varied levels of exposure among participants and therefore allow for the assessment of intervention intensity on key outcomes.

- The mental health problems and risk profiles of male and female adolescents varied significantly, suggesting that future interventions should be further tailored to address culturally accepted gender norms and unique mental health and other needs of male and female adolescents, and offer youth development approaches that build targeted life skills.

- Future research among vulnerable migrant adolescents requires more intensive follow-up efforts, and should be designed with sufficient sample sizes to account for potential high rates of loss to follow up due to the significant mobility of this population. 


\section{INTRODUCTION}

\section{BACKGROUND}

With almost 97 million people (World Bank 2014) and a low, but steadily rising HIV prevalence (1.5 percent among 15-49 year olds), Ethiopia is poised to ramp-up targeted HIV prevention efforts across the country (UNAIDS 2013). While the national HIV prevalence among youth remains low at 1 percent among 15-24 year olds, prevalence has reached 9 percent in some regions among young women (Ethiopian Demographic and Health Survey [EDHS] 2011). Risk of infection is higher among young people living in urban settings, including Addis Ababa (1.7 percent female, 0.2 percent male) (EDHS 2011). Overall, national data demonstrate an increasingly urban female-centered epidemic, with a 3 to 2 female-to-male ratio of HIV infection and an urban prevalence of 7.7 percent, compared to a rural prevalence of less than 1 percent (Ministry of Health $[\mathrm{MOH}]$ and Federal HIV/AIDS Prevention and Control Office [FHAPCO] 2007). Thus, young women in urban areas are most at risk for HIV infection.

Over the last several decades Ethiopia has seen a steady increase in rural to urban migration (Erulkar et al. 2006). Many young women and men migrate to urban areas, such as Addis Ababa, to seek employment and educational opportunities. In a study of 1,000 adolescents aged 10-19 living in slums of Addis Ababa, 45 percent of those migrants were females with little or no education (Erulkar et al. 2006).

Migrant adolescents are frequently subjected to unstable living conditions, disputes with family members or employers, or other types of childhood trauma, and often end up as "street kids" (Lalor 1999; Morantz et al. 2013; Gregorowski and Seedat 2013). It is widely established that street children are prone to several physical problems, including adverse effects of sexual activity and drug misuse (Scanlon et al. 1998; Ajayi and Torimiro 2004). Support programs, such as Retrak Ethiopia ${ }^{1}$, are helping to mitigate the effects of street living for these adolescents while making efforts to reconnect them to their families and facilitate their return to home town/village.

When young people leave school and migrate they begin to spend considerably more time on paid and unpaid work. Boys tend to spend more time in recreational and social activities and boys living in the street are more likely to experience sexual abuse and engage in drug use, increasing their HIV risk (Tadele 2009; Hagos 2009). Migrant girls spend more time in unpaid domestic work and may work in physically or sexually abusive environments, increasing their HIV risk (Erulkar et al. 2006). The 2010 UN Declaration of Commitment on HIV/AIDS report notes that 14 percent of clients of female sex workers are between 17 and 24 years old, indicating that adolescent males are in fact engaging in risky behaviors. The same report noted that documented female sex workers across major towns in the country are on average age 22, and about one third of them are under the age of 20 years (FHAPCO 2010). A 2004 study by Erulkar and colleagues found that migrant Ethiopian girls have notably fewer friends and less social support than boys. At the same time, they are more likely to feel discomfort in their neighborhood, with many reporting being scared of some of their neighbors and having experienced harassment or sexual assault (Erulkar et al. 2004).

\footnotetext{
${ }^{1}$ http://retrak.org/About.aspx
} 
Not only do difficult living situations inherently add to the HIV risk profile of adolescents in Ethiopian cities, but research shows a strong bidirectional relationship between mental health illness and difficult living circumstances (WHO 2003; Ashenafi et al. 2000; Desta 2008). This relationship predicts a high prevalence of mental health disorders in marginalized and vulnerable populations with difficult living situations such as child domestic workers, street children, children who serve as the head of their household, and child sex workers. Mental health issues among migrant adolescents likely amplify HIV risk, as those with mental health issues are also more likely to engage in risky sexual behavior and are at increased risk of being victims of sexual violence. Negative psychosocial outcomes have also been associated with linkages between social and environmental factors, such as being a young person living in isolation or in urban areas, and sexual abuse in Ethiopia (Ashenafi et al. 2000; Wondie 2011; Jemal 2012).

In order to promote positive social participation and individual well-being, identifying and treating mental health problems early in child or adolescent development is highly recommended (WHO 2003). Early emotional and physical abuse can impair optimal cognitive and emotional development (Andrés et al. 1999), which can lead to increased risk of mental and behavioral disorders (Last et al. 1996). Thus, it is critical to identify and address mental health problems, which heighten HIV risk, as early as possible to avoid negative social and health outcomes for adolescents. However, knowledge about how targeted mental health interventions can impact HIV-related outcomes worldwide, and in Ethiopia, remains limited.

The purpose of this study was to reduce this knowledge gap by pilot testing a strategy for addressing mental health and psychological problems among marginalized children in Addis Ababa, Ethiopia. With support from the United States Agency for International Development (USAID) and under the HIVCore task order, the Population Council's Biruh Tesfa program, in collaboration with Retrak Ethiopia, evaluated whether addressing mental health issues and providing targeted psychosocial counseling to this high-risk group could result in reductions in HIV risk behavior and increased use of HIV services.

\section{DEVELOPMENT OF MENTAL HEALTH SCREENING TOOL AND TARGETED INTERVENTION}

This report presents findings from the third phase of the overarching study "Addressing Mental Health Disorders and HIV Vulnerability of Marginalized Adolescents in Addis Ababa, Ethiopia," which comprised three phases:

Phase I was completed in December 2012. It was a formative study that included a qualitative needs assessment to determine the type and extent of mental health and psychological needs among adolescent migrants living in Addis Ababa. This study found sexual abuse among migrant adolescents linked to psychological trauma (Jani and Schenk 2014). In addition, the majority of young migrants experienced social isolation and unstable living situations and engaged in high risk sexual behavior. Additionally, few migrant adolescents displayed comprehensive HIV prevention knowledge (Jani and Schenk 2014). Based on these findings the study expert committee developed a targeted counseling intervention consisting of individual and group counseling sessions, art and creative therapy, and community engagement events. 
Phase II, completed in February 2013, included the adaptation of a mental-health screening tool among high-risk adolescents in Addis Ababa. The adaptation was guided by a study expert committee which comprised a psychologist, a psychometrician, psychiatrists, study PIs, and program staff from Retrak and Biruh Tesfa. Four mental-health screening tools were examined by the study expert committee, including the Youth Self-Report tool (YSR), Strengths Difficulties Questionnaire (SDQ), Symptoms Checklist (SCL) 90-R, and the Symptom Assessment (SA) 45-Questionnaire. The committee considered the applicability of these tools in Ethiopia based on the following criteria: guidance available for administration, scoring, and results interpretation; ease of administration; applicability of the tool for the target age group; and adequate coverage range of mental health conditions, including anxiety and depression. The YSR was chosen as the most appropriate tool for use and adaptation among the study population; it was tested for reliability among high-risk adolescent populations in Ethiopia and validated against a gold standard of clinical diagnosis by licensed psychiatrists. The YSR provides scores on eight empirically derived syndromes: anxious/depressed, withdrawn/depressed, somatic complaints, social problems, thought problems, attention problems, rule-breaking behavior, and aggressive behavior. The YSR was found to have sufficient reliability and validity in identifying young vulnerable women with anxiety/depression and/or social problems, and young men with attention problems, which were the most common mental health disorders observed by psychiatrists among this population (Geibel et al. manuscript under review).

This report presents findings from Phase III of the research study, completed in January 2014, which aimed to evaluate 1) how the targeted psychosocial counseling intervention, developed in Phase I, affected the prevalence of mental health disorders among at-risk migrant youth in Addis Ababa, as measured by the adapted YSR developed in Phase II; and 2) how the targeted psychosocial intervention affected uptake of HIV services and mitigated HIV risk behaviors, as measured by a behavioral survey. 


\section{METHODOLOGY}

\section{AIM}

The study investigated how the provision of a targeted counseling intervention and psychosocial support services to marginalized young people in Addis Ababa impacted their mental health and responsiveness to HIV programs and services.

\section{OBJECTIVES}

Pilot test a targeted psychosocial support counseling intervention and measure any effects on:

1. Psychological and mental health problems of the target population.

2. Responsiveness to HIV programming and services among the target population.

\section{ROUTINE SERVICES}

This pilot study was conducted among adolescents receiving social services in Addis Ababa. Young women were recruited through the Biruh Tesfa project while young men were recruited through Retrak.

The Population Council, in partnership with the Regional Bureaus of Women Children and Youth Affairs, operated the Biruh Tesfa program. Biruh Tesfa (Amharic for "bright future") mentors offer education, lifeskills training, and mentoring to young women as well as referral services to counselors, psychologists, and medical staff as needed. Biruh Tesfa partnered with the Organization for the Prevention, Rehabilitation and Integration of Female Street Children (OPRIFS), to offer medical care, reproductive health services, and shelter to young women aged 7-24 who are victims of violence (Jani and Schenk 2014).

Retrak Ethiopia offers similar services and alternative options to street boys across Ethiopia. Retrak is a non-governmental organization (NGO) that works with male street youth ages 7-17 to gain access to education, workforce training, healthcare, shelter, and protection. Street children are provided with counseling services, food, and shelter with the ultimate aim of living independently as an active member of the community, or facilitating a return home to their families where possible. ${ }^{2}$ When young men are initially recruited into Retrak, they are evaluated by trained counselors using the SDQ ${ }^{3}$ (Strengths and Difficulties Questionnaire) to assess their mental health well-being. As part of Retrak's standard program structure, young men are assigned individual counselors for the duration of their stay with the program, alongside constructive play time and art therapy sessions.

Prior to the implementation of this phase of the study, both programs identified the need for a psychosocial support intervention aimed to reduce the psychological and mental health problems of urban youth and to improve uptake of HIV services and reduce risky behavior among their beneficiaries.

\footnotetext{
${ }^{2} \mathrm{http}: / /$ retrak.org/About.aspx

${ }^{3}$ http://www.sdqinfo.org/a0.html
} 


\section{STUDY POPULATION AND ELIGIBILITY}

Eligible adolescents were required to be registered recipients of services from Biruh Tesfa or Retrak in the past three months, age 15-18 years old, and able to provide informed consent. While Biruh Tesfa and Retrak provide services to both older and younger people outside this age range, the minimum age to participate in the study was 15 years old, due to ethical and consent considerations. The upper age limit of 18 years was chosen because it is the age limit for which the YSR instrument was validated (see Ethical Considerations section for further age justification).

\section{STUDY DESIGN}

This was a before and after intervention study design. Participants were screened using the YSR tool and a behavioral survey at baseline. A pilot psychosocial counseling intervention was provided for a period of three months, followed by an endline YSR and behavioral survey. Due to ethical concerns, those screened with severe mental health issues at baseline $(\mathrm{N}=24)$ were referred to clinical services for appropriate treatment and follow-up care, and thus were excluded from the study. The methodology for determining the YSR cut-off scores is discussed further in the Measurement section below.

\section{SAMPLE SIZE AND RECRUITMENT PROCEDURE}

Based on client volume at the two organizations, all eligible participants who consented to participate in the study were recruited. In June 2013, a total of 576 female participants at Biruh Tesfa were screened and recruited into the study. Of these participants, 19 completed the adapted YSR survey but had one or more severe mental health problems and thus referred for mental health care and were not enrolled in the study (Figure 1). Following the 3-month intervention period, 315 females were re-interviewed at endline.

For male participants, the intervention and behavioral surveys were staggered into three cohorts corresponding to their Retrak groups. For each cohort a baseline survey was conducted followed by the intervention and an endline survey. The baseline survey for the first cohort of young men was conducted in July 2013 and the endline survey for the last cohort was completed in January 2014. At baseline five males were identified with severe mental health issues and thus referred for mental health care and not enrolled in the study. For the three cohorts combined a total of 154 participants were interviewed in the baseline survey and 102 participants were re-interviewed in the endline survey (Figure 1).

\section{DESCRIPTION OF THE INTERVENTION}

A pool of study counselors was recruited to deliver the intervention at Biruh Tesfa and Retrak. All counselors had a bachelor's degree in psychology, social work, or a related field. Ten female counselors and one counseling supervisor were hired to work with the young women at Biruh Tesfa. A total of four male and two female counselors and one female counselor supervisor were hired for the study intervention at Retrak. Both sets of counselors were trained using a standard training curriculum that was developed by the study team with inputs from both service delivery organizations. Topics included adolescent development and health, including HIV-related topics; psychological wellbeing and mental health problems; factors increasing vulnerability of marginalized adolescents; concepts of counseling and ethical issues in counseling; counseling theories, skills, and processes; group counseling; creative therapies; and music, drama, and dance (MDD) therapies. The training lasted for one week and culminated with a practicum session. Biruh Tesfa counselors were trained first, as the intervention implementation began 
Figure I Participant flow chart

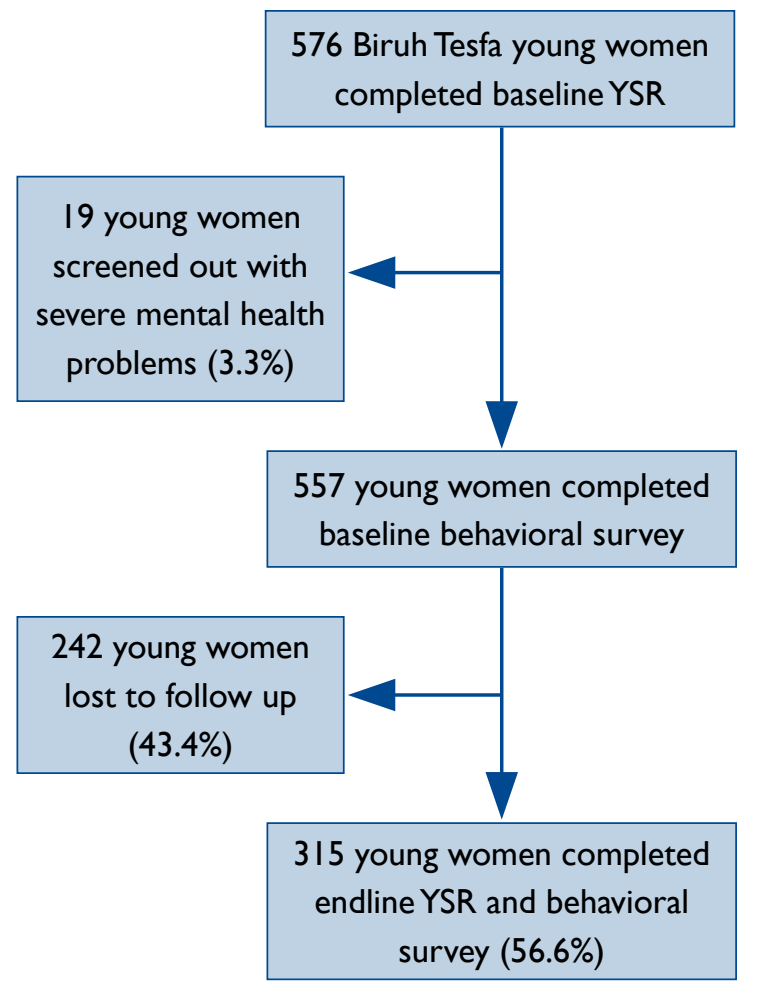

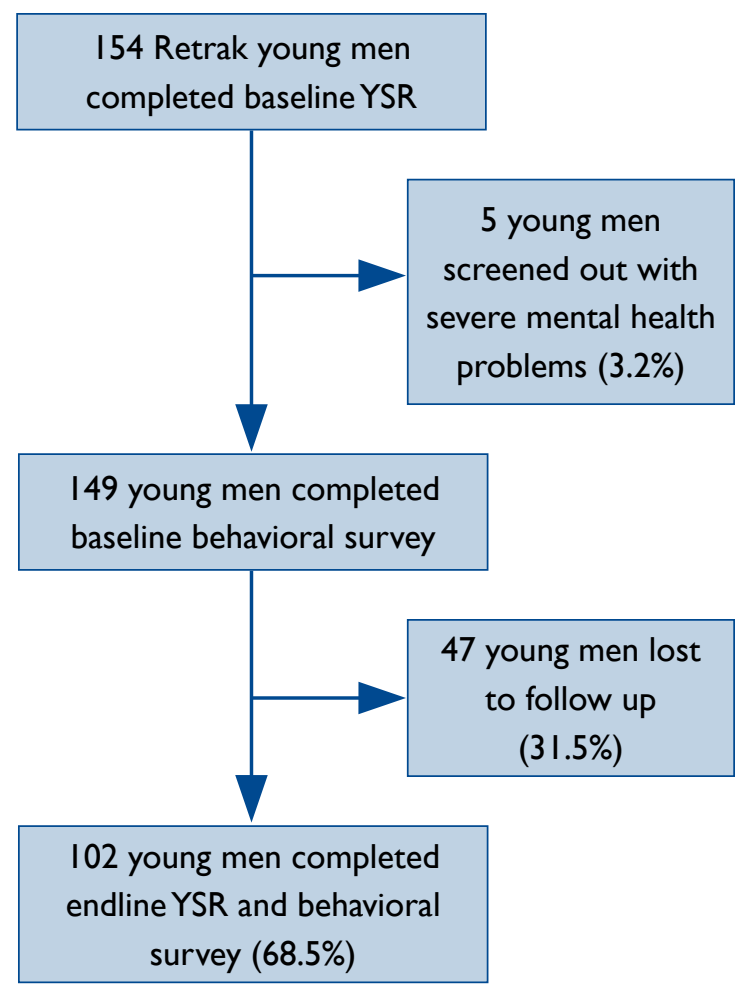

among the young women first. The same set of trainers trained the Retrak counselors one month later. A mid-point meeting was held between both Biruh Tesfa and Retrak counselors, as well as their supervisors, to review experiences and discuss suggestions to overcome challenges encountered in delivering the intervention.

Peer support services (PSS) and peer-based interventions are built on the premise that those with mental illness can offer help and support to others. This idea has become increasingly popular and could help increase the efficacy of structured self-management programs for mental health disorders (Cook 2009). In order to encourage peer support our study intervention included group counseling and creative art and MDD therapies as an avenue to discuss personal, sensitive issues in a supportive, group environment. This unique and supportive structure allowed for deeper rooted, emotional problems to surface and be discussed and dealt with among peers who may have been experiencing similar issues. This component of the intervention was developed in direct response to findings from interviews with service providers at Biruh Tesfa and Retrak in the formative study (Phase I), who explicitly requested capacity building training on creative therapies to address the unique problems that their beneficiaries were facing (Jani and Schenk 2014).

Study counselors administered the targeted counseling intervention, which included both individual and group counseling sessions, to all enrolled Biruh Tesfa and Retrak participants. Counselor supervisors, who were on site during the study intervention, met with all study counselors on a daily basis to discuss challenges, provide support to the counselors, and prepare weekly schedules for future counseling sessions. They also served as substitute counselors when a regular counselor was unable to conduct a session as planned. 
All enrolled participants were engaged in an initial one-on-one counseling session lasting approximately 60 minutes with their assigned study counselor. The first one-on-one counseling session was used to determine the future course of counseling for each participant. These sessions were client driven, as counselors were trained to structure each session using the following client-centered approach: 1) exploring main issue(s)/problem(s) brought forth by the client; 2) discussing possible options/solutions to address the aforementioned issue(s) and the pros/cons of each option; 3) supporting the client to develop a plan of action to address his/her problem(s). The counselor also made sure to cover topics of sexual health and HIV/AIDS (knowledge, risks, and prevention strategies), alcohol and drug abuse, and experience with violence, as appropriate, with each participant during the client-driven discussion by probing whether any of these issues were present in the past or currently present. The counselors maintained a counseling record book to keep track of the issues discussed in the counseling sessions using these three broad categories and to enable follow-up in the next session. If a participant did not bring up any issues in the first client driven session, but the counselor believed that $\mathrm{s} / \mathrm{he}$ would benefit from further counseling to discuss deep rooted emotions that may not have been brought out in the individual counseling, then the participant was referred for a follow-up session in the format of group counseling art therapy, or MDD. The participant would then be assessed again by his/her counselor and referred for further group or individual counseling as appropriate.

Thus, based on client feedback from the initial counseling session, counselors recommended respondents for additional one-on-one sessions, group counseling with other participants who may be experiencing similar issues, MDD or creative therapy sessions, or none at all, if no specific concerns or problems were alluded to or divulged. All subsequent counseling sessions were decided in a similar manner. The purpose of group therapy was to create a setting for participants who may not have been able to express themselves openly in a one-to-one setting to feel comfortable in discussing difficult issues in a larger, communal setting with their peers.

\section{MEASUREMENT}

\section{Adapted YSR questionnaire}

The adapted YSR questionnaire consists of 105 items for eight syndrome scales (anxious/depressed, withdrawn/depressed, somatic complaints, social problems, thought problems, attention problems, rule-breaking behaviors, and aggressive behavior), an internalizing problem scale (combining scores from anxious/depressed, withdrawn/depressed, and somatic complaints), an externalizing problem scale (combining scores from rule breaking behavior and aggressive behavior), and a total scale (all scores combined). These scales were designed to approximate diagnosis from the Diagnostic and Statistical Manual of Mental Disorders, 4th Edition (DSMV IV) (American Psychiatric Association 2000).

While the original YSR is meant to be self-administered, due to the low and varying levels of literacy among the study population, the study team opted to administer the tool orally to respondents to ensure accurate understanding and responses. The adapted YSR tool was therefore administered by trained clinical nurses.

In Phase II of this study the team evaluated the reliability and validity of the YSR as a screening tool for mental health problems among this target population. After being administered the YSR questionnaire each study participant received a clinical mental assessment by a licensed Ethiopian psychiatrist who 
made a clinical diagnosis independent of the YSR questionnaire. As explained in the next paragraph, the resultant scores from the YSR questionnaire were compared by an expert committee to the independent diagnosis by the psychiatrist as a gold standard to determine locally acceptable cut-off points for diagnosing the syndromes measured by the tool. The study expert committee, comprising Ethiopian psychiatrists, psychologists, service providers, health professionals, and the research team, met to determine acceptable cut-off points for each of the syndrome scales within the Ethiopian setting. Among the nine syndromes measured using the YSR tool the expert committee only determined cut-off scores for four syndromes (anxiety disorder, social problems, attention problems, and aggressive behavior) for which there was sufficient prevalence in this population.

The YSR questionnaire asks specific questions that are aimed to diagnose a particular syndrome. If a respondent answers "yes" to all the questions for that syndrome the respondent is diagnosed with that syndrome. However, for respondents who answer "yes" to some but not all questions for a syndrome, a decision has to be made regarding the cut-off point. In the process of adaptation of an international tool to a specific setting, that cut-off point is usually determined as the score that gives the best sensitivity and specificity of the tool in diagnosing the syndrome in comparison to a gold standard. This approach has been used in other studies validating and adapting psychometric tools in Africa (Ventevogel et al.2014). In our study the gold standard was the psychiatrist clinical examination.

For anxiety disorder there were 13 items:

1. Cries a lot

2. Fears

3. Fears school

4. Fears doing bad things

5. Must be perfect

6. Feels unloved

7. Feels worthless
8. Nervous

9. Fearful

10. Feels too guilty

11. Self-conscious

12. Thinks of suicide

13. Worries

Using sensitivity and specificity the expert committee came up with the cut-off scores for anxiety disorder that differed by gender- 6.5 items out of 13 for females and 4.5 items out of 13 for males. For the rest of the syndromes the cut-off scores were the same for males and females. For social problems there were 11 items and the cut-off score was 2.5 items out of 11 items:

1. Dependent

2. Lonely

3. Doesn't get along

4. Jealous

5. Others out to get him/her

6. Accident prone
7. Gets teased

8. Not liked

9. Clumsy

10. Prefers younger kids

11. Speech problem 
For attention problems there were 9 items and the cut-off score was 3.5 items out of 9 items:
1. Acts young
6. Daydreams
2. Fails to finish
7. Impulsive
3. Can't concentrate
8. Poor schoolwork
4. Can't sit still
9. Inattentive
5. Confused

For aggressive behavior there were 17 items for which the cut-off score was 2.5 items out of the 17 items:

1. Argues a lot

2. Mean

3. Demands attention

4. Destroys own things

5. Destroys others things

6. Disobedient at home ("home" was replaced with the "Retrak center" in the case of males)

7. Disobedient at school (at their respective service delivery organizations in this case);

8. Gets in fights
9. Attacks people

10. Screams a lot

11. Stubborn, sullen

12. Mood changes

13. Suspicious

14. Teases a lot

15. Temper

16. Threatens others

17. Loud

\section{Determination of cut-off scores for severe mental health issues}

After the overall cut-off scores were determined, the study expert committee met once again to decide on the optimum cut-off scores for each syndrome at the mild, moderate, and severe level, as shown in Table below.

\section{Table I Cut-off scores by severity of syndrome}

\begin{tabular}{|lcccc|}
\hline Syndrome & \multicolumn{4}{c|}{ Cutoff scores } \\
& Mild & Moderate & Severe & Overall \\
\hline Anxious/depressed & 3.5 & 5.5 & 12 & 5.5 \\
Social problems & 2.5 & 3.5 & 7 & 3.5 \\
Attention problems & - & - & - & 3.5 \\
Aggressive behavior & - & - & - & 2.5 \\
\hline
\end{tabular}

Based on these data the expert committee decided that two syndromes (anxious/depressed and social problems) will be considered independently to determine the severe cases that were excluded from the intervention. 
As noted earlier, it was not possible to determine cut-off points for the remaining syndromes since the study psychiatrists did not diagnose enough cases with those syndromes, perhaps due in part to a small sample size, or because those cases are rare in this population.

The statistical analyses used in the validation are discussed in a separate paper (Geibel et al. under review).

\section{Behavioral surveys}

To measure changes in responsiveness to HIV programs and in HIV-related behavior, a behavioral survey was developed based on adapted versions of existing, previously tested tools, such as the EDHS, and other HIV-related knowledge, attitude, and practices (KAP) surveys. The resultant survey tool covered the following topics: sexual vulnerability, sexual abuse, knowledge of HIV and program services, intention of engaging with HIV prevention services, actual engagement with these services, HIV preventative actions, sexual violence, self-efficacy, and gender issues. Seven HIV-related indicators were assessed: Knowledge of HIV, perceived HIV risk (low, medium, or high), ever tested for HIV, ever had sex, knew a place to test for HIV, use of sexual and reproductive health (SRH) service in the past three months, and discussed HIV issue in the past year. With regard to HIV knowledge the EDHS knowledge scale was used to generate the variable of having comprehensive knowledge of HIV. According to EDHS, comprehensive knowledge of $\mathrm{HIV}$ is indicated if respondents correctly answer the following five questions: 1) can reduce HIV risk by having one sexual partner; 2) can get AIDS from mosquito bites; 3) can reduce HIV by using a condom; 4) can get AIDS as a result of witchcraft; 5) a healthy looking person can have HIV.

\section{DATA ANALYSIS}

Survey data was analyzed in STATA version 13. First, we generated simple frequencies and means to describe key characteristics of the study population and key mental health and HIV-related outcomes at baseline. We also compared those lost to follow up with those who completed both baseline and endline surveys using baseline data. Because the females and males had different living situations and history of migration, we analyzed their data separately.

To assess changes in key outcomes over time, we used McNemar's test, as the key indicators were all dichotomous. McNemar's test was used to assess the significance of the difference between two correlated proportions, as in this study where the two proportions of a variable at baseline and endline are based on the same sample of subjects. We also used generalized estimating equation (GEE) to assess the association between mental health and the improvement in mental health status and HIV related outcomes over time. The analysis was performed on the sample of 315 young women and 102 young men (those who completed both baseline and endline surveys).

GEE was chosen because it has been widely used for analyzing repeated measure data and it allows us to account for both between subjects and within subject variance. The regression model can be illustrated as below:

Logit $($ y/outcome $)=\beta_{0}+\beta_{1} I * M H+\beta_{2} *$ Time $+\beta_{3} *($ time $* M H$ interaction $)+\varepsilon$

This model allows us to determine whether there is a relationship between mental health and HIV-related outcomes, as well as assess the relationship between mental health improvement and key HIV-related 
indicators. Six regression models for six key HIV-related indicators were performed and presented in tables $7 \mathrm{a}$ (young women) and $7 \mathrm{~b}$ (young men) on page 22. The regression models accounted for the panel data structure/correlated data using both baseline and endline data.

To assess the association between the different intervention exposure levels and key outcome indicators among young women, we used endline data to examine the relationship between key mental health indicators and exposure to one intervention session versus exposure to two or more intervention sessions. No additional analysis was conducted among young men for this variable, as the vast majority of the cohort received four intervention sessions.

Informed by Phase 2 of this study, four key mental health indicators were selected for measuring changes associated with the intervention. Each of the four indicators was dichotomized at cut-off points (discussed above). An additional variable of any mental health issue was created that measured if a participant had any of the above described four mental health disorders.

Due to low reliability of the gender-scale measure among this population, it was not included in the analysis. Reporting of drug and alcohol uses were also too low and thus were not included in bivariate or multivariate-level data analysis.

\section{ETHICAL CONSIDERATIONS}

The study protocol, instruments, and informed consent forms were reviewed and approved by the Institutional Review Board of the Population Council and the Addis Ketema Sub-City Health Office. Research activities involving adolescents followed guidance outlined in Ethical Approaches to Gathering Information from Children and Adolescents in International Settings: Guidelines and Resources (Schenk and Williamson 2005). Considering the vulnerability of these adolescents-migrants not living with their parents-it was important to obtain community "consent" before approaching individual participants for consent. Community support and buy-in for this study was generated through service providers at both Biruh Tesfa and Retrak who informed their service participants about the study and addressed any questions to ensure a proper understanding of the purpose and process of the study by the participants. In addition, all interviewers were trained on research ethics and special considerations when working with adolescents.

All participants provided separate, written informed consent for both the YSR Questionnaire and the Behavioral Survey. The legal age of consent for research in Ethiopia is 18 years of age, (Tekola et al. 2009) while the service recipients of these two organizations included children as young as 7 years of age. However, the study team chose the lower age limit to be 15 years as a fairly mature age to gather adequate information from, as it is also the cut-off age used in the Demographic Health Survey (DHS). Furthermore, young people living outside of parental care can be considered to be "emancipated minors" (Santelli et al. 2003) who have been defined to be otherwise living independently of their own parents, and have a right to making decisions about receiving services without necessitating parental or guardian consent. We did not wish to deny these "mature minors" their right to participate in research that could be used to improve services for them (Meade and Slesnick 2002). For this reason study participants aged 15 to 17 years (emancipated minors) also signed the same adult consent form as that signed by participants who had attained 18 years, the age of majority in Ethiopia. 
During the informed consent process, all participants were informed of their right to refuse participation or to withdraw from the study at any time without affecting their right to receive services at their existing program site. Respondents were also informed that they would not receive any form of compensation for their participation in the study.

Participants were informed that engaging in the interview may touch upon sensitive issues, such as physical and sexual violence, and that if they felt uncomfortable at any point during the interview they could decline further participation in the interview. Trained counselors remained on call during the interview process at both program sites to provide care for any participant who required it during administration of the screening tool or behavioral survey. Counselors also provided referral slips for further mental health care or psychosocial counseling to participants as needed.

As noted in the sample size and recruitment procedure section (Figure 1) adolescents who were identified, using the YSR questionnaire, as having severe mental health problems ceased participation in the interview and study, and were referred to immediate, further care. 


\section{KEY FINDINGS}

\section{SOCIO-DEMOGRAPHIC CHARACTERISTICS AND MENTAL HEALTH STATUS AT BASELINE}

Baseline characteristics are reported below in Table 2.

\section{Males}

About 53 percent of young men were aged 17 or 18 years old and 47 percent were aged 15 or 16 years old. Respondents were asked where they lived before moving to Addis Ababa. The majority of male respondents migrated to Addis Ababa from a rural village (37.4 percent) or from a small town (36.1 percent). The majority of the young men (55.7 percent) were Orthodox Christian while 30.9 percent reported being Muslim, and the remaining 13.4 percent reported being Protestant.

Over half of the sample (55.7 percent) had attained 1-5 years of schooling while 42 percent had attained 6-11 years of schooling. Literacy levels for young men were moderate. Nearly three-fourths of the sample (70.6 percent) could read part of or the entirety of a sentence in a local language, while 29.4 percent could not read at all. A majority of young men had temporary employment (39 percent), while over onethird (37.9 percent) were self-employed, and 15.8 percent were unemployed.

One third of young men at baseline (34.2 percent) kept in touch with their family. Very few young men in the sample reported being sexually active ( 6.7 percent). A very small percentage ( 2.0 percent) reported experiencing sexual violence while 18 percent reported experiencing physical violence.

With regard to mental health status at baseline, the majority of young men (71.8 percent) had at least one of the four mental-health/psychosocial problems (social problem, attention problem, anxiety problem, or aggressive behavior).

\section{Females}

The female sample was slightly younger than males, with 62.8 percent of them aged 15 or 16 years old. The rest were 17 or 18 years old. Over three-fourths of young women (77.8 percent) reported Orthodox Christian as their main religion, and 15.1 percent reported being Muslim. About two-thirds of the sample reported having migrated to Addis Ababa from a rural area. The majority of young women (64.4 percent) categorized themselves as being permanently employed. Only 15.3 percent considered themselves to be temporarily employed and 11 percent said they were unemployed.

Similar to young men, all of the female respondents enrolled at baseline had a primary school education; 54 percent had achieved $1-5$ years of schooling while the remaining 46 percent had 6-11 years. Approximately 70 percent of the female sample could read part of or an entire sentence in a local language.

A majority of the females were living with their family or relatives (70.7 percent) and for this reason the majority of them, nearly 90 percent, reported keeping in touch with their family. 
Only three young women reported being sexually active ( 0.6 percent). A slightly greater percentage (1.8 percent) reported experiencing sexual violence, while 2 percent reported physical violence. Unlike the young men, only about one-third of the young women (37.3 percent) had at least one of the four mental-health/psychosocial problems (social problem, attention problem, anxiety problem, or aggressive behavior).

\section{Table 2 Descriptive characteristics of the study population at baseline*}

\begin{tabular}{|c|c|c|}
\hline & $\begin{array}{c}\text { Males }(\mathrm{N}=149) \\
\text { Percent }(n)\end{array}$ & $\begin{array}{c}\text { Females }(\mathbf{N}=557) \\
\text { Percent }(n)\end{array}$ \\
\hline \multicolumn{3}{|l|}{ Age } \\
\hline $15-16$ years & $47.3(70)$ & $62.8(350)$ \\
\hline $17-18$ years & $52.7(78)$ & $37.2(227)$ \\
\hline \multicolumn{3}{|l|}{ Education } \\
\hline I-5 years of schooling & $57.7(86)$ & $54.0(301)$ \\
\hline $6-11$ years of schooling & $42.3(63)$ & $46.0(256)$ \\
\hline \multicolumn{3}{|l|}{ Literacy levels } \\
\hline Can't read at all & $29.4(35)$ & $28.8(156)$ \\
\hline Read part of a sentence & $14.3(17)$ & $20.5(111)$ \\
\hline Read whole sentence & $56.3(67)$ & $50.7(275)$ \\
\hline \multicolumn{3}{|l|}{ Religion } \\
\hline Orthodox & $55.7(83)$ & $77.7(433)$ \\
\hline Muslim & $30.9(46)$ & I5.I (84) \\
\hline Protestant & $13.4(20)$ & $7.2(40)$ \\
\hline \multicolumn{3}{|l|}{ Currently living with relative or family } \\
\hline Yes & $\mathrm{n} / \mathrm{a}$ & 70.7 (394) \\
\hline No & & $29.3(163)$ \\
\hline \multicolumn{3}{|l|}{ Place lived previously } \\
\hline Addis Ababa & $11.6(17)$ & $19.0(106)$ \\
\hline Other city & $14.9(22)$ & $2.7(15)$ \\
\hline Small town & 36.1 (53) & $10.4(58)$ \\
\hline Rural village & $37.4(55)$ & $67.9(378)$ \\
\hline \multicolumn{3}{|l|}{ Work status** } \\
\hline Unemployed & $15.8(15)$ & $11.0(26)$ \\
\hline Temporary employment & $39.0(37)$ & $15.3(36)$ \\
\hline Permanent employment & $0.0(0)$ & $64.4(152)$ \\
\hline Self-employed & $37.9(30)$ & $7.6(18)$ \\
\hline Other & $7.4(7)$ & $1.7(4)$ \\
\hline \multicolumn{3}{|l|}{ Keep in touch with family } \\
\hline Yes & $34.2(5 \mathrm{I})$ & $87.4(485)$ \\
\hline No & $65.8(98)$ & $12.6(70)$ \\
\hline \multicolumn{3}{|l|}{ Ever had sex } \\
\hline Yes & $6.7(10)$ & $0.6(3)$ \\
\hline No & 93.3 (139) & $99.4(496)$ \\
\hline Ever experienced physical violence & $18.6(19)$ & $3.8(21)$ \\
\hline Ever experienced sexual violence & $2.0(2)$ & $1.8(10)$ \\
\hline \multicolumn{3}{|l|}{ Mental health indicators } \\
\hline Had social problem & $49.0(73)$ & I5.8 (88) \\
\hline Had attention problem & $36.2(54)$ & $10.0(56)$ \\
\hline Had anxiety problem & $47.0(70)$ & $21.5(120)$ \\
\hline Had aggressive behavior & $15.4(23)$ & $23.0(128)$ \\
\hline Had any mental health problem & $71.8(107)$ & $37.3(208)$ \\
\hline
\end{tabular}

*Some sample sizes for cells may not add up to the total $\mathrm{N}$ due to missing values

** Work data was only available for $n=246$ young women and $n=95$ young men 


\section{BASELINE CHARACTERISTICS OF STUDY PARTICIPANTS LOST TO FOLLOW-UP}

Table 3 compares study participants who had completed both baseline and end line surveys with those who were lost to follow-up at endline.

\section{Males}

Overall, those lost to follow up and those who completed the study were comparable with regard to key characteristics. However, the study did lose more young men who had higher literacy levels, fewer anxiety problems, and more aggressive behavior.

\section{Females}

For young women, the two groups were significantly different across age, literacy levels, religion, and social problems. In particular, we lost more young women who were in the 17-18 age group and had lower levels of literacy.

\section{Table 3 Comparison of participants with complete data and those lost to follow-up}

\begin{tabular}{|c|c|c|c|c|c|c|}
\hline & \multicolumn{3}{|c|}{ Males $(\mathrm{N}=\mid 49)$} & \multicolumn{3}{|c|}{ Females $(\mathbf{N}=557)$} \\
\hline & $\begin{array}{c}\text { Complete } \\
(n=102)\end{array}$ & $\begin{array}{l}\text { Lost to } \\
\text { follow up } \\
(n=47)\end{array}$ & p-value & $\begin{array}{c}\text { Complete } \\
(n=3 \mid 5)\end{array}$ & $\begin{array}{l}\text { Lost to } \\
\text { follow up } \\
(n=242)\end{array}$ & p-value \\
\hline Age & & & 0.650 & & & 0.013 \\
\hline $15-16$ & $47.1(48)$ & $51.1(24)$ & & $67.3(212)$ & $57.0(138)$ & \\
\hline $17-18$ & $52.9(54)$ & $48.9(23)$ & & $32.7(103)$ & $43.0(104)$ & \\
\hline Education & & & 0.510 & & & 0.132 \\
\hline $\mathrm{I}-5$ years & $55.9(57)$ & $61.7(29)$ & & $56.8(179)$ & $50.4(122)$ & \\
\hline $6-11$ years & $44.1(45)$ & $38.3(18)$ & & $43.1(136)$ & $49.6(120)$ & \\
\hline Literacy levels & & & 0.002 & & & 0.030 \\
\hline Can't read at all & $33.8(26)$ & $21.4(9)$ & & $24.7(76)$ & $34.2(80)$ & \\
\hline Read part of the sentence & $20.8(16)$ & $2.4(\mathrm{I})$ & & $20.1(62)$ & $20.9(49)$ & \\
\hline Read whole sentence & $45.5(35)$ & $76.2(32)$ & & $55.2(170)$ & $44.9(105)$ & \\
\hline Religion & & & 0.354 & & & 0.040 \\
\hline Orthodox & $52.0(53)$ & $63.8(30)$ & & $79.4(250)$ & $75.6(183)$ & \\
\hline Muslim & $34.3(35)$ & $23.4(\mathrm{II})$ & & $15.9(50)$ & I4.I (34) & \\
\hline Protestant & $13.7(14)$ & $12.8(6)$ & & $4.7(15)$ & $10.3(25)$ & \\
\hline Place lived previously & & & 0.613 & & & 0.075 \\
\hline Addis Ababa & $10.0(10)$ & $14.9(7)$ & & $22.9(72)$ & I4.I (34) & \\
\hline Other city & $16.0(16)$ & $12.8(6)$ & & $2.5(8)$ & $2.9(7)$ & \\
\hline Small town & $34.0(34)$ & $40.4(19)$ & & $9.8(3 \mathrm{I})$ & $11.2(27)$ & \\
\hline Rural village & $40.0(40)$ & $31.9(15)$ & & $64.8(204)$ & $71.9(174)$ & \\
\hline \multicolumn{7}{|l|}{ Mental health indicators } \\
\hline Social problem & $51.0(52)$ & $44.7(21)$ & 0.475 & I3.3(42) & $19.0(46)$ & 0.07 \\
\hline Attention problem & $37.3(38)$ & $34.0(16)$ & 0.705 & $8.6(27)$ & $12.0(29)$ & 0.18 \\
\hline Anxiety problem & $53.9(55)$ & $31.9(15)$ & 0.012 & $20.0(63)$ & $23.6(57)$ & 0.31 \\
\hline Aggressive behavior & $10.8(\mathrm{II})$ & $25.5(12)$ & 0.021 & $24.4(77)$ & $2 \mathrm{I} . \mathrm{I}(5 \mathrm{I})$ & 0.34 \\
\hline Any mental health problem & $75.5(77)$ & $63.8(30)$ & 0.142 & $34.9(110)$ & $40.5(98)$ & 0.18 \\
\hline
\end{tabular}




\section{EXPOSURE TO INTERVENTION ACTIVITIES}

Table 4 provides a breakdown of the intervention exposure, indicating how many overall counseling sessions (combined individual, group, or creative/arts therapy) were administered before the endline survey was conducted. It is notable that the majority of young women (81.6 percent) received only one counseling session while the majority of young men (92.1 percent) received four counseling sessions. This difference could reflect the dissimilar structure of service delivery of Retrak compared to Biruh Tesfa. Retrak provides a semi-residential service to the young men recruited in the program, including a place to sleep, meal provision, and literacy catch-up classes, thus allowing young men to be more available to receive multiple sessions with counselors. On the other hand, Biruh Tesfa provides services at its centers to young women who live and work in households in the community. Hence, young women would only come in contact with the counselors when they were given leave from their employers to attend the Biruh Tesfa centers.

\section{Table 4 Exposure to intervention activities}

\begin{tabular}{|lcc|}
\hline & Males \% (N) & Females \% (N) \\
\hline I session & $1.0(1)$ & $81.6(257)$ \\
2 sessions & $2.9(3)$ & $9.8(31)$ \\
3 sessions & $3.9(4)$ & $2.5(8)$ \\
4 sessions & $92.1(94)$ & $6.0(19)$ \\
\hline
\end{tabular}

\section{CHANGES IN KEY MENTAL HEALTH INDICATORS}

Table 5 below shows the differences in key mental health conditions between baseline and endline surveys, as determined by bivariate analysis.

Among males no significant associations were seen between exposure to the study intervention and the following mental health outcomes: anxiety, social problems, and attention problems. For aggressive behavior, not enough young men presented with this syndrome at endline to enable a comparison.

Among young women, significant reductions in key mental health conditions were observed. In particular, at baseline, 8.6 percent of young women presented with attention problems, while at endline this number reduced to 4.8 percent $(\mathrm{p}<.05)$. Similarly, the prevalence of aggressive behavior also decreased from 24.4 percent to 13 percent $(\mathrm{p}<.01)$, resulting in an overall decrease of the prevalence of any mental health problems from 34.9 percent at baseline to 15.1 percent at endline $(\mathrm{p}<.01)$. 
Table 5 Key mental health indicators

\begin{tabular}{|lccc|ccc|}
\hline Variable & \multicolumn{3}{c|}{ Males (N=102) } & \multicolumn{3}{c|}{ Females (N=3 I 5) } \\
Had: & $\begin{array}{c}\text { Baseline } \\
\%(\mathbf{N})\end{array}$ & $\begin{array}{c}\text { Endline } \\
\%(\mathbf{N})\end{array}$ & p-value & $\begin{array}{c}\text { Baseline } \\
\%(\mathbf{N})\end{array}$ & $\begin{array}{c}\text { Endline } \\
\%(\mathbf{N})\end{array}$ & $\begin{array}{c}\text { p-value } \\
\text { Anxiety problem }\end{array}$ \\
Social problem & $54.0(55)$ & $52.0(53)$ & 0.720 & $20.0(63)$ & $14.9(47)$ & 0.070 \\
Attention problem & $51.0(53)$ & $52.0(52)$ & 0.870 & $13.3(42)$ & $8.9(28)$ & 0.070 \\
Aggressive behavior & $37.3(38)$ & $38.2(39)$ & 0.880 & $8.6(27)$ & $4.8(15)$ & 0.050 \\
Any mental health problem & n/a: too many missing value at endline & $24.4(77)$ & $13.0(41)$ & 0.001 \\
\hline
\end{tabular}

*Notes:Table only includes respondents with complete baseline and endline data; $\mathrm{p}$-value corresponds to McNemar test

\section{CHANGES IN HIV-RELATED INDICATORS}

Table 6 demonstrates the changes in HIV-related indicators associated with the study intervention. Too few respondents reported ever having had sex, therefore further analyses were not performed on sexual behavior.

\section{Males}

There were significant changes in several HIV-related indicators. At baseline, about one fifth of male respondents had comprehensive HIV knowledge (20.6 percent); this increased significantly to 34.3 percent at endline $(\mathrm{p}<.05)$. Males also demonstrated a significant increase in knowing a place to test for HIV, from 88.2 percent at baseline to 95.1 percent at endline $(\mathrm{p}<.05)$ and ever having tested for HIV, 45.1 percent to 69.6 percent $(\mathrm{p}<.001)$. While not significant, it is interesting to note that the proportion of males considering themselves to be at medium or high level of HIV risk increased from 23.5 percent to 27.5 percent.

The males' use of SRH services also significantly increased from 31.4 percent at baseline to 54.9 percent at endline $(\mathrm{p}<.001)$ as well as their reporting of discussing SRH issues in the last three months $(51.1$ percent baseline and 71.6 percent endline; $\mathrm{p}<.01$ ).

\section{Females}

Similar to males, female participants also had significant increases in comprehensive HIV knowledge from baseline (16.8 percent) to endline ( 24.4 percent; $\mathrm{p}<.05$ ). Additionally, young women experienced significant increases in knowledge of a place to get tested for HIV (68.5 percent baseline to 77.2 percent endline $(\mathrm{p}<.01))$, and in ever being tested for HIV $(29.8$ percent baseline to 36.1 percent endline $(\mathrm{p}<$ $.01)$ ).

While use and discussion of SRH services also increased among young women from baseline to endline, these findings were not significant. Although also not significant, unlike among young men, the proportion of young women who perceived themselves to be at medium or high level of HIV risk decreased from 48.9 percent at baseline to 45.4 percent at endline (NS).

However, with regard to changes in HIV risk perception, it is not clear whether this implies a positive or negative response. On one hand a decreased HIV risk perception could imply that the individual has 
become complacent and is denying risk. On the other hand it may imply that they feel they have taken substantive steps to reduce their risks through behavior change.

Table 6 Changes in key HIV-related indicators

\begin{tabular}{|lccc|ccc|}
\hline Variable & \multicolumn{3}{c|}{ Males (N=1 02) } & \multicolumn{3}{c|}{ Females (N=3 I5) } \\
& Baseline & Endline & p-value & Baseline & Endline & p-value \\
\hline Had comprehensive knowledge of HIV & $20.6(21)$ & $34.3(35)$ & 0.040 & $16.8(53)$ & $24.4(77)$ & 0.014 \\
$\begin{array}{l}\text { Perceived medium and high level of HIV } \\
\text { risk perception (compared to low level) }\end{array}$ & $23.5(24)$ & $27.5(28)$ & 0.510 & $17.1(54)$ & $14.3(45)$ & 0.290 \\
Knew a place to test for HIV & $88.2(90)$ & $95.1(97)$ & 0.05 & $68.6(216)$ & $77.2(243)$ & 0.009 \\
Ever tested for HIV & $45.1(46)$ & $69.6(7 I)$ & $<0.001$ & $29.8(86)$ & $36.1(104)$ & 0.000 \\
Use of SRH service in the past 3 months** & $31.4(32)$ & $54.9(56)$ & 0.001 & $48.9(154)$ & $45.4(143)$ & 0.310 \\
Discussed SRH issues past 3 months & $51.0(12)$ & $71.6(33)$ & 0.002 & $48.9(81)$ & $45.1(69)$ & 0.330 \\
\hline
\end{tabular}

Notes:

Analysis was performed on those who have complete baseline and endline data; p-values correspond to McNemar test; Gender equitable scale was not usable due to low reliability; Medium and high risk were collapsed into one category.

"Use of SRH services includes visits to and use of various public or government health facilities and services. Retrak employs a nurse on staff who provides HIV testing and counseling, access to condoms, and other health services as needed to Retrak males. Females at Biruh Tesfa are provided health care referral slips, free of charge, to access public health facilities as needed. These health facilities also provide HIV testing and counseling and access to contraception, among other services.

\section{ASSOCIATION BETWEEN RATES OF CHANGES IN MENTAL HEALTH ON HIV-RELATED INDICATORS}

Tables $7 \mathrm{a}$ and $7 \mathrm{~b}$ show data on whether rates of changes in mental health (pre and post) were associated with changes in HIV-related outcomes. The significant and positive interaction terms in Table 7a suggest that rates of changes in mental health were associated with "having comprehensive knowledge of HIV" and "perceived HIV risk" among female participants. None of these effects was found among male participants. 
Table 7a Changes in mental health status and HIV knowledge and perceptions among females ( $n=3$ I 5; GEE regression results; longitudinal data)

\begin{tabular}{|c|c|c|c|c|c|c|}
\hline & $\begin{array}{c}\text { Had } \\
\text { comprehensive } \\
\text { knowledge of } \\
\text { HIV } \\
\text { AOR }^{\dagger} \\
(95 \% \mathrm{CI})\end{array}$ & $\begin{array}{c}\text { Perceived } \\
\text { HIV risk } \\
\text { AOR } \\
(95 \% \mathrm{Cl})\end{array}$ & $\begin{array}{c}\text { Tested for } \\
\text { HIV } \\
\text { AOR } \\
(95 \% \mathrm{CI})\end{array}$ & $\begin{array}{c}\text { Knew a } \\
\text { place to } \\
\text { test for } \\
\text { HIV } \\
\text { AOR } \\
(95 \% \mathrm{CI})\end{array}$ & $\begin{array}{l}\text { Discussed } \\
\text { HIV/STI } \\
\text { issue } \\
\text { AOR } \\
(95 \% \mathrm{CI})\end{array}$ & $\begin{array}{c}\text { Used SRH } \\
\text { service } \\
\text { AOR } \\
(95 \% \mathrm{Cl})\end{array}$ \\
\hline \multicolumn{7}{|l|}{$\begin{array}{l}\text { Had any mental } \\
\text { health issue }\end{array}$} \\
\hline No & 1.0 & 1.0 & 1.0 & 1.0 & 1.0 & 1.0 \\
\hline Yes & $\begin{array}{c}0.2 \\
(0.05-0.89)^{*}\end{array}$ & $\begin{array}{c}0.2 \\
(0.03-0.68)^{*}\end{array}$ & $\begin{array}{c}0.6 \\
(0.19-1.80)\end{array}$ & $\begin{array}{c}0.9 \\
(0.28-2.88)\end{array}$ & $\begin{array}{c}0.3 \\
(0.11-1.03)\end{array}$ & $\begin{array}{c}0.6 \\
(0.20-1.57)\end{array}$ \\
\hline \multicolumn{7}{|l|}{ Time } \\
\hline Baseline & 1.0 & 1.0 & 1.0 & 1.0 & 1.0 & 1.0 \\
\hline Endline & $\begin{array}{c}1.1 \\
(0.70-1.80)\end{array}$ & $\begin{array}{c}0.53 \\
(0.32-0.89)^{*}\end{array}$ & $\begin{array}{c}1.4 \\
(0.94-1.96)\end{array}$ & $\begin{array}{c}1.6 \\
(1.02-2.34)^{*}\end{array}$ & $\begin{array}{c}0.7 \\
(0.48-1.10)\end{array}$ & $\begin{array}{c}0.8 \\
(0.53-1.10)\end{array}$ \\
\hline $\begin{array}{l}\text { Interaction term } \\
\text { (Time*MH) }\end{array}$ & $\begin{array}{c}3.1 \\
(1.30-7.50)^{*}\end{array}$ & $\begin{array}{c}3.3 \\
(1.30-8.60)^{*}\end{array}$ & $\begin{array}{c}1.5 \\
(0.72-2.98)\end{array}$ & $\begin{array}{c}0.9 \\
(0.40-2.01)\end{array}$ & $\begin{array}{c}1.9 \\
(0.90-3.90)\end{array}$ & $\begin{array}{c}1.4 \\
(0.70-2.70)\end{array}$ \\
\hline
\end{tabular}

Notes: $A O R=$ Adjusted odds ratio; HIV-related indicators/dependent variables are binary $(0=$ no, I=yes $) ; A O R=I .0$ indicates the reference category; Key socio-demographics characteristics (age, education, marital status, and religion) are adjusted for in the model (data not shown).

"significant at $\mathrm{p}<0.05$

Table $7 \mathrm{~b}$ Changes in mental health status and HIV-related indicators among males ( $n=102$; GEE regression results)

\begin{tabular}{|c|c|c|c|c|c|c|}
\hline & $\begin{array}{c}\text { Had } \\
\text { comprehensive } \\
\text { knowledge of } \\
\text { HIV } \\
\text { AOR }^{\dagger} \\
(95 \% \mathrm{Cl})\end{array}$ & $\begin{array}{c}\text { Perceived } \\
\text { HIV risk } \\
\text { AOR } \\
(95 \% \mathrm{Cl})\end{array}$ & $\begin{array}{c}\text { Tested for } \\
\text { HIV } \\
\text { AOR } \\
(95 \% \mathrm{Cl})\end{array}$ & $\begin{array}{c}\text { Knew a } \\
\text { place to } \\
\text { test for } \\
\text { HIV } \\
\text { AOR } \\
(95 \% \mathrm{CI})\end{array}$ & $\begin{array}{c}\text { Discussed } \\
\text { HIVISTI } \\
\text { issue } \\
\text { AOR } \\
(95 \% \mathrm{CI})\end{array}$ & $\begin{array}{c}\text { Used SRH } \\
\text { service } \\
\text { AOR } \\
(95 \% \mathrm{Cl})\end{array}$ \\
\hline \multicolumn{7}{|l|}{$\begin{array}{l}\text { Had any mental } \\
\text { health issue }\end{array}$} \\
\hline No & 1.0 & 1.0 & 1.0 & 1.0 & 1.0 & 1.0 \\
\hline Yes & $\begin{array}{c}0.2 \\
(0.14-2.64)\end{array}$ & $\begin{array}{c}0.9 \\
(0.08-9.70)\end{array}$ & $\begin{array}{c}1.0 \\
(0.15-6.00)\end{array}$ & $\begin{array}{c}13.6 \\
(0.46-406.0)\end{array}$ & $\begin{array}{c}5.9 \\
(0.7-52.3)\end{array}$ & $\begin{array}{c}3.2 \\
(0.36-30.2)\end{array}$ \\
\hline \multicolumn{7}{|l|}{ Time } \\
\hline Baseline & 1.0 & 1.0 & 1.0 & 1.0 & 1.0 & 1.0 \\
\hline Endline & $\begin{array}{c}0.5 \\
(0.11-3.50)\end{array}$ & $\begin{array}{c}1.0 \\
(0.27-3.74)\end{array}$ & $\begin{array}{c}3.1 \\
(1.20-8.40)^{*}\end{array}$ & $\begin{array}{c}9.2 \\
(1.02-82.6)^{*}\end{array}$ & $\begin{array}{c}3.3 \\
(1.1-10.5)^{*}\end{array}$ & $\begin{array}{c}4.8 \\
(1.4-15.4)^{*}\end{array}$ \\
\hline $\begin{array}{l}\text { Interaction term } \\
\text { (Time*MH) }\end{array}$ & $\begin{array}{c}5.4 \\
(0.99-30.50) \\
\end{array}$ & $\begin{array}{c}1.3 \\
(0.28-5.80) \\
\end{array}$ & $\begin{array}{c}0.9 \\
(0.29-3.10) \\
\end{array}$ & $\begin{array}{c}0.2 \\
(0.01-2.60) \\
\end{array}$ & $\begin{array}{c}0.7 \\
(0.20-2.70) \\
\end{array}$ & $\begin{array}{c}0.5 \\
(0.12-1.80) \\
\end{array}$ \\
\hline
\end{tabular}

Notes: $\mathrm{AOR}=$ Adjusted odds ratio; HIV-related indicators/dependent variables are binary $(0=$ no, I=yes); AOR $=1.0$ indicates the reference category; Key socio-demographics characteristics (age, education, marital status, and religion) are adjusted for in the model (data not shown).

*significant at $\mathrm{p}<0.05$ 
Table 8a shows the end line mental health outcomes for females by level of exposure to counseling sessions (one session was the median and used as a cut-off point). No significant differences were found. Because the vast majority of young men received four or more counseling sessions (94 males out of 102), and a majority of females only received one counseling session, no stratified analysis could be conducted on either population.

Table 8a Relationship between levels of exposure and mental health outcomes at endline (among females)

\begin{tabular}{|c|c|c|c|}
\hline \multirow{2}{*}{$\begin{array}{l}\text { Variable } \\
\text { Had: }\end{array}$} & \multicolumn{3}{|c|}{ Females $(n=3 \mid 5)$} \\
\hline & $\begin{array}{c}\text { Received one session } \\
\% \text { (N) }\end{array}$ & $\begin{array}{c}\text { Received } \geq 2 \text { sessions } \\
\% \text { (N) }\end{array}$ & p-value \\
\hline Anxiety problem & I5.6 (4I) & $10.3(6)$ & 0.28 \\
\hline Social problem & $9.0(23)$ & $8.6(5)$ & 0.94 \\
\hline Attention problem & $4.7(12)$ & $5.2(3)$ & 0.87 \\
\hline Aggressive behavior & $11.7(30)$ & $9.6(11)$ & 0.14 \\
\hline Any mental health problem & $26.1(67)$ & $20.7(12)$ & 0.39 \\
\hline
\end{tabular}

Table $8 \mathrm{~b}$ below demonstrates the relationship between females' exposure to the intervention and their HIV-related outcomes. No statistically significant associations were found between exposure and HIVrelated indicators.

Table 8b Relationship between levels of exposure and HIV-related outcomes at endline (among females)

\begin{tabular}{|lccc|}
\hline Variable & $\begin{array}{c}\text { Females }(\mathbf{n}=\mathbf{3} \text { I5) } \\
\text { Received one session } \\
\%(\mathbf{N})\end{array}$ & $\begin{array}{c}\text { Received } \geq \mathbf{2} \text { sessions } \\
\%(\mathbf{N})\end{array}$ & p-value \\
\hline Had comprehensive knowledge of HIV & $23.7(61)$ & $27.6(16)$ & 0.53 \\
High level of perceived HIV risk & $14.4(37)$ & $27.6(16)$ & 0.91 \\
Knew a place to test for HIV & $76.7(197)$ & $79.3(46)$ & 0.66 \\
Ever tested for HIV & $37.1(91)$ & $32.8(19)$ & 0.53 \\
Use of SRH service in the past 3 months & $44.0(113)$ & $51.7(3)$ & 0.28 \\
\hline
\end{tabular}




\section{DISCUSSION}

\section{SAMPLE CHARACTERISTICS}

This study aimed to evaluate how a targeted counseling intervention and psychosocial support services to marginalized adolescents in Addis Ababa affected their mental health and responsiveness to HIV programs and services.

The study was designed to pilot an intervention focused on addressing the vulnerabilities of young men and women who had migrated to Addis Ababa from small towns or rural villages. Adolescents migrate to cities for a number of reasons, including looking for employment, poverty, family disintegration, peer pressure, family influence, city life attraction, parental abuse, and school failure (Jani and Schenk 2014; Yizengaw and Gebiresilus 2014).

The population we recruited comprised male and female adolescents aged 15 to 18 years, less than half of whom had attained 6-11 years of education; the majority had only attained 1-5 years of schooling, and about 30 percent were illiterate. In Ethiopia, children are supposed to enter primary school at age 7 (Federal Ministry of Education 2013) and by 15 years should have attained at least eight years of education, indicating that our study population of migrant adolescents had less access to education than those in the general population.

The data also showed some gender differences in characteristics which could influence the vulnerabilities and risk profiles of young males and females. A higher proportion of females than males migrated from rural villages ( 68 percent vs 38 percent) while a higher proportion of males than females migrated from small towns (36 percent vs 10 percent). The majority of young women worked as domestic help, 64.4 percent categorizing themselves as being permanently employed, 70 percent living with family relatives, and 87.4 percent reporting to be in touch with their family. On the other hand, the majority of young men lived on the streets and worked odd jobs, none considered themself permanently employed, none of them was living with a relative, and only 34.2 percent were in touch with family.

The study showed that while the proportion reporting having ever experienced physical violence was only 3.8 percent among females at baseline, it was 18.6 percent among males. The level of reported sexual violence was low in both genders (about 2 percent). It is also notable that although reported sexual activity was low in both genders, males reported more sexual activity than females (6.7 percent vs 0.6 percent). There was also a gender difference in the prevalence of mental health problems at baseline- 37.3 percent among females and 71.8 percent among males. Our Phase 1 formative study found that females appear to have been assigned to traditional gender roles of caring and providing services for the family, which have often been associated with vulnerabilities such as over work, under payment, and restricted freedom of movement (Jani and Schenk, 2014; Erulkar et al. 2007). Male study participants, on the other hand, appear to have taken on more traditional male gender roles of free living and risk taking, confirming what has been documented by other studies among vulnerable adolescent populations (Yizengaw et al. 2014). These typical male behaviors can be associated with physical violence or the hardship of the street life that they face. 


\section{IMPLEMENTATION OF THE INTERVENTION}

The two organizations providing services to these young people appear to have tailored their service delivery models to the gender difference in the needs, risks, and vulnerabilities of these migrant young people. Young men and women in the study lived in substantially different living circumstances and followed associated cultural gender norms that dictate allowable and acceptable behavior among males and females. It is possible that since males' and females' living arrangements were not similar at baseline, they may have responded differently to the intervention.

Retrak provides young men with services using a semi-residential approach where the service recipients are given a place to sleep, meals, literacy catch-up lessons, health education, life skills training, and psychological counseling. In this situation the young men had a good amount of time to receive routine services.

Meanwhile, Biruh Tesfa provides services to young women at various center locations, allowing them to receive literacy classes, counseling, and referral for health care services as and when they are able to attend. Most young women lived in homes with either family members or their employers. The majority of the young women were employed as domestic house help, which traditionally denotes a hierarchical relationship between the young woman and her family/employer. Young women were likely less able to return for follow-up counseling sessions due to demanding work schedules or fear of their family or employers' disapproval. Evidence of these restrictive gender norms was documented in the formative phase of this study as well (Jani and Schenk 2014). Hence, the young women had limited time to receive routine services. The study lost more young women who had lower levels of literacy and reported having social problems. The effects of social isolation and associated fear of reprimand from their employers could have made some young women less willing or able to leave their homes (Jani and Schenk 2014) to continue study participation. In line with these differences, our findings showed that while 92.1 percent of the males received four targeted intervention counseling sessions, 81.6 percent of the females received just one intervention counseling session.

\section{PROGRAMMATIC DIFFERENCES}

The intervention provided individual, group counseling, MDD, and creative therapy modalities. Individual counseling sessions were client driven-issues were only addressed by the counselor if the client brought them up-so it is possible that many young women received only the initial counseling session because they did not present with issues that needed to be explored in further counseling sessions. Counselor supervisors also reported that some young women informed their counselors that they may not be able to return for subsequent sessions, so counselors may have felt obliged to cover as many essential content topics as possible relating to young women's mental health and vulnerability in the first counseling session. Many young women who were referred for further individual or group counseling likely did not return to the Biruh Tesfa centers due to competing work demands and fear of repercussion from their family members or employers. This also posed a barrier for young women to return for the endline assessment. Additionally there were several different Biruh Tesfa centers in the Addis Ababa catchment area that were included in the study, proving more challenging for study counselors and program mentors to trace young women who did not attend their scheduled counseling sessions. 
The targeted counseling for young males was more structured compared to the method of administering the intervention to young women. This is partly due to the existing structure of the Retrak Drop-in Centre which, prior to this study, was providing onsite counseling on a regular basis, as well as due to the fewer number of males overall included in the study sample. Many young men received overnight care at Retrak facilities, in addition to receiving standard daytime Retrak services making it easier to trace young men for the study intervention counseling sessions. This added convenience of the drop-in centre facility structure bypassed the additional burden of explaining the need and importance of the counseling intervention to Retrak staff and to the young men and/or their employers. We should also note that it is possible that more literate young men dropped out of the study intervention before their endline assessment. It is our speculation that they found employment that required them to reduce the amount of time they spent with the Retrak program. One of Retrak's main goals is to rehabilitate young men back with their families to their home town/village when possible, after assessing the child's well-being with his family and providing mediation and parenting skills to families as needed. Accordingly, some young men who were enrolled in the study may not have received the intervention for the full 12 week period if their reintegration schedule necessitated them to leave Addis sooner than the study endline assessment.

In randomized control trials counseling interventions combined with group therapy have been shown to reduce mental health problems among marginalized youth in an African setting (Betancourt et al. 2014; O'Callaghan et al. 2013). A randomized control trial of a Youth Readiness Intervention (YRI), consisting of evidence-based common practice elements from cognitive-behavioral therapy (CBT) and group interpersonal therapy (IPT) to address co-occurring mental health symptoms and functional problems, was conducted among war-affected youth in Sierra Leone. The study revealed that, compared to the control, youth who received 10 sessions of YRI improved their emotional and behavioral functioning following the intervention (Betancourt et al. 2014). Trauma-focused cognitive behavioral therapy (TFCBT) was tested among 12- to 17-year-old war-affected young women in Democratic Republic of Congo and found to reduce symptoms of depression, anxiety, and conduct problems; and increase prosocial behavior among those randomized to the intervention compared to those in the control (O'Callaghan et al. 2013). Our data suggest the possibility that the targeted counseling intervention that we piloted may have reduced mental health problems and improved HIV-related indicators, and could be a basis for further investment of resources to design a more scientifically rigorous study among this priority population of vulnerable migrant adolescents.

\section{DOCUMENTED CHANGES}

Despite a short piloting period, our data suggest that the intervention was associated with positive effects on key mental-health outcomes among young women. Females experienced significant improvements in three out of six HIV-related outcomes (HIV knowledge, knowledge of a place to test for HIV, and getting tested for HIV). In addition, young women's improvement in mental health status was positively associated with having comprehensive knowledge of HIV and perception of being at risk for HIV.

Among the young men, while there was no statistically significant change in the prevalence of mental health outcomes, there were significant improvements in HIV-related indicators, including comprehensive knowledge of HIV, knowing a place to test for HIV, ever having tested for HIV, use of SRH services, and their reporting of discussing SRH issues in the last three months. As explained above, for males who had 
more severe mental health problems than females, a longer intervention period might be needed in order to see an impact.

As noted by Retrak Ethiopia Director Dr. Lynn Kay, when young men first arrive at Retrak they appear quiet and withdrawn. Once they develop a trusting relationship with Retrak staff, they feel safe and able to express pent up anger and frustration, which also often leads to more demands. Retrak staff also noted that outward displays of anger are often an anticipated stage in the males' rehabilitation, and typically last until they are reintegrated back with their families. Most young men either lived at the Retrak center, with friends, or in the street. Young men typically only stay at Retrak for half day sessions from Monday to Friday, while some also spend the night at the night shelter as needed. It can be assumed that the times during which the young men are not at the Retrak center they are out in the streets or at their place of employment, for those who have jobs. Females' living arrangements were very different than young men in that they generally had less mobility and fewer social freedoms (Jani and Schenk 2014). Males' prolonged exposure to street life may have hardened the participants and made them less likely to respond to the three-month intervention efforts (Kay 2015). A longer intervention exposure may be necessary to see a demonstrated improvement in the males' mental health.

Due to the cultural expectations that young women be more quiet and submissive, especially those from more rural areas (Jani and Schenk 2014), it is possible that young women did not articulate their experiences and challenges as clearly as young men at the outset of the study intervention. It is also possible that females experienced a significant decrease in three separate mental health outcomes because the nature of the counseling intervention may have indirectly been more appropriate for or geared toward young women, rather than young men, making them more actively engaged in the intervention and resulting in greater improved mental health outcomes than the males.

Current literature suggests that a moderate amount of variance in patient outcomes may be attributable to therapist differences. Lutz and colleagues found that 5-10 percent of the variance in across-session change in symptom intensity among patients receiving psychotherapy could be attributed to differences in therapists (Lutz et al. 2007). Since in our study different cadre of staff delivered counseling at both organizations it is possible that the intervention delivery could have differed in important ways that was not directly assessed in the study.

Lastly, since participants were recruited into the study by the program staff from whom they were already receiving services, our results may not apply to participants who have not found their way to services yet.

\section{LIMITATIONS}

The study has several limitations. First, it had no comparison group due to the inability to recruit a larger population for an experimental study design. This limits our ability to assess the true impact of the interventions on key outcomes: participants might have received mental health and HIV-related interventions from other services. However, given the short intervention period (three months), contamination was less likely. Second, it is possible that sexual activity and/or sexual abuse data was under reported among this population, in part due to a desirability or recall bias, especially in the context of a face-to-face interview. While the limitations to self-reported data are well known, especially among adolescents and regarding sensitive topics such as sexual behavior (Weinhardt et al. 1998; Munzy and 
Schwebeke 2015), research has also found that self-report measures, such as the YSR tool in this study, are necessary to continue assessing health-risk behaviors among adolescents (Brener et al. 2003).

Since so few participants reported any experience with sexual activity, we had limited ability to conduct any further analysis of sexual risk behavior as originally anticipated, such as condom use, number of sexual partners, and experience with sexual violence. Third, due to time, financial, and logistical constraints, including the transition of the management of the Biruh Tesfa program, the study intervention was only able to be delivered for three months. Additionally, a core tenet of Retrak's service delivery model is to re-integrate their beneficiaries with their families after they graduate from the Retrak program, as and when desired and possible. This was another reason why the study team had to limit the intervention to three months because as per their service delivery model, most young men who are eligible and willing, are typically re-integrated with their families within three monthsof arriving at Retrak. Thus in order to limit the loss to follow-up among young men who may have left the program for rehabilitation, the study team decided to limit the intervention to three months. Because the male participants had more severe mental health problems at baseline, they may have required a more intensive counselling intervention program, and for a longer period of time, in order to see a significant change. The Biruh Tesfa program was in its final stages of operation under Population Council's leadership, ending December 2013. Staff were being transitioned off the project, which impacted the number of mentors who remained available to assist study counselors to follow up with study participants to attend subsequent counseling sessions and participate in the endline survey. Oftentimes mentors also negotiated with the young women's relatives/ employers to inform them about the benefit of their attendance and involvement with Biruh Tesfa activities

Lastly, the study had a high rate of loss to follow up, especially among female participants. This affects the statistical power in detecting significant changes in mental health outcomes, especially among male participants where the sample size at baseline was already small. The high rate of loss to follow up is likely the result of several transitions at the two service delivery organizations, as mentioned above. In addition, without the institutional implementation of regular counseling therapy, young women from Biruh Tesfa likely faced additional resistance from their families and employers in gaining permission to attend followup counseling sessions. 


\section{RECOMMENDATIONS}

- After administering the targeted, three-month intervention we observed that mental health problems for vulnerable female adolescents were reduced and HIV-related indicators for both vulnerable male and female adolescents improved. However we cannot attribute these changes to our study intervention because we did not have a control group, thus we cannot rule out confounding factors. Therefore future studies may benefit from a more robust study design (e.g., experimental design or having a control group).

- Our study was limited to a three-month pilot due to resource limitations. Therefore future studies may benefit from a longer intervention period in order to see an impact, especially among males. In addition, a longer intervention period could also allow for varied levels of exposure among participants and therefore allow for the assessment of intervention intensity on key outcomes (e.g., dose-response analysis).

- The mental health problems and risk profiles of male and female adolescents varied significantly, suggesting that future interventions should be tailored to address culturally-accepted gender norms and unique mental health needs of male and female adolescents, and offer cross-sectoral youth development approaches that build life skills targeted for this group of vulnerable adolescents.

- Future research among vulnerable migrant adolescents likely will require more intensive follow-up efforts, and should be designed with sufficient sample sizes to account for the potential high rates of loss to follow up due to the mobility of this marginalized group. 


\section{REFERENCES}

Ajayi, A. O., and D. O. Torimiro. 2004. "Perspectives on child abuse and labour: global ethical ideals versus african cultural realities," Early Child Development and Care 174(2): 183-191.

American Psychiatric Association, ed. 2000. Diagnostic and statistical manual of mental disorders: DSMIV-TR ${ }^{\oplus}$. American Psychiatric Pub.

Andrés, M., M. Catalá, and M. Gómez-Beneyto. 1999. "Prevalence, comorbidity, risk factors and service utilisation of disruptive behaviour disorders in a community sample of children in Valencia (Spain)," Soc Psychiatry Psychiatr Epidemiol. 34: 175-179.

Ashenafi, Y. et al. 2000. "Socio-demographic correlates of mental and behavioural disorders of children in southern Ethiopia," East Afr Med J. 77(10): 565-9.

Betancourt, T.S. et al. 2014. "A behavioral intervention for war affected youth in Sierra Leone: a randomized control trial," Journal of the American Academy of Child \& Adolescent Psychiatry 53(12): 12881297.

Brener, N., J. Billy, and W. Grady. 2003. "Assessment of factors affecting the validity of self-reported health-risk behavior among adolescents: evidence from the scientific literature," Journal of Adolescent Health 33(6): 436-457.

Central Statistical Agency [Ethiopia] and ICF International. 2012. "Ethiopia Demographic and Health Survey 2011.” Addis Ababa, Ethiopia and Calverton, Maryland, USA: Central Statistical Agency and ICF International.

Cook, J. et al. 2009. "Initial outcomes of a mental illness self-management program based on wellness recovery action planning," Psych Services 60: 246-249.

Desta, M. 2008. "Epidemiology of child psychiatric disorders in Addis Ababa, Ethiopia." Umeå, Sweden: Department of Clinical Sciences, Umeå University.

Erulkar, A. and A. Ferede. 2007. "Social exclusion and early or unwanted sexual initiation among poor urban females in Ethiopia," International Perspectives on Sexual and Reproductive Health 35(4).

Erulkar, A. et al. 2006. "Migration and vulnerability among adolescents in slum areas of Addis Ababa, Ethiopia," J Youth Stud 9(3): 361-374.

- 2004. "Adolescent life in low income and slum areas of Addis Ababa, Ethiopia." New York: Population Council.

Federal HIV/AIDS Prevention and Control Office (FHAPCO). 2010. "Report on progress towards implementation of the UN Declaration of Commitment on HIV/AIDS, 2010.” Addis Ababa: Federal Democratic Republic of Ethiopia, FHAPCO. 
Federal Ministry of Education (FMOE). 2013. Ethiopia Education Statistics Annual Abstract 20122013. Addis Ababa: FMOE. http://www.moe.gov.et/English/Resources/Documents/eab05.pdf.

Geibel, S. et al. 2015. "Reliability and validity of an interviewer-administered adaptation of the Youth Self-Report for mental health screening of vulnerable young people in Ethiopia," PLOS One, under review.

Gregorowski, C. and S. Seedat. 2013. "Addressing childhood trauma in a developmental context," J Child Adolesc Ment Health (2):105-118.

Hagos, S. and D. Haile Mariam. 2009. "Assessment of HIV/AIDS related risks among Men Having Sex with Men (MSM) in Addis Ababa, Ethiopia,” J Public Health Policy (3):269-79.

Jani, N. and K. Schenk. 2014. "Formative research to develop an intervention for addressing mental health/psychosocial issues and HIV vulnerability of marginalized adolescents in Addis Ababa, Ethiopia," HIVCore Formative Report. Washington, DC: USAID | Project Search: HIVCore.

Jemal, J. 2012. "The child sexual abuse epidemic in Addis Ababa: some reflections on reported incidents, psychosocial consequences and implications," Ethiop J Health Sci. (1):59-66.

Joint United Nations Programme on HIV/AIDS (UNAIDS). 2013. "Global report: UNAIDS report on the global AIDS epidemic 2013.” Geneva: UNAIDS.

Kay, Lynn. 2015. Email communication on March 18.

Lalor, K. 1999. “Street children: a comparative perspective," Child Abuse \& Neglect. 23(8): 759-770.

Last, C. et al. 1996. "A prospective study of childhood anxiety disorders," J Am Acad Child Adolesc Psychiatry 35: 1502-1510.

Lutz, W. et al. 2007. "Therapist effects in outpatient psychotherapy: A three-level growth curve approach," Journal of Counseling Psychology 54(1): 32-39.

Meade, M., and N. Slesnick. 2002. "Ethical considerations for research and treatment with runaway and homeless adolescents," Journal of Psychology 136(4): 449-463.

$\mathrm{MOH}$ (Ethiopia) and FHAPCO. 2007. "Single point HIV prevalence estimate." Addis Ababa: MOH Ethiopia.

Morantz, G. et al. 2013. "Child abuse and neglect among orphaned children and youth living in extended families in sub-Saharan Africa: What have we learned from qualitative inquiry?," Vulnerable Child Youth Studies 8(4): 338-352.

Munzy, C., and J. Schwebeke. 2015. "Accuracy of self-report of sexual activity among adolescent girls: implications for interpretation of vaginal flora patterns," mBio 6(3):e00819-15. doi:10.1128/ mBio.00819-15.

O'Callaghan, P. et al. 2013. "A randomized controlled trial of trauma-focused cognitive behavioral therapy for sexually exploited, war-affected Congolese girls," Journal of American Academy of Child and Adolescent Psychiatry 52(4): 331-448. 
Santelli, J. et al. 2003. "Guidelines for adolescent health research: A position paper of the society for adolescent medicine," Journal of Adolescent Health 33: 396-409.

Scanlon, T. J. et al. 1998. "Street children in Latin America," BMJ : British Medical Journal 316(7144): $1596-1600$.

Schenk, K. D. and J. Williamson 2005. Ethical Approaches to Gathering Information among Children and Adolescents in International Settings: Guidelines and Resources. Washington DC: Horizons/Population Council, Family Health International/Impact, United States Agency for International Development.

Tadele, G. 200. "Unrecognized victims: sexual abuse against male street children in Merkato area, Addis Ababa," Ethiopian Journal of Health Development 174-82.

Tekola, F. et al. 2009. "Tailoring consent to context: designing an appropriate consent process for a biomedical study in a low income setting," PLoS Negl Trop Dis 3(7): e482. doi:10.1371/journal. pntd.0000482.

Ventevogel, P. et al. 2014: "Validation of the Kirundi versions of brief self-rating scales for common mental disorders among children in Burundi," BMC Psychiatry 14: 36.

Weinhardt, L. et al. 1998. "Reliability and validity of self-report measures of HIV-related sexual behavior: Progress since 1990 and recommendations for research and practice," Archives of Sexual Behavior 27: 155-180.

WHO. 2003. "Caring for children and adolescents with mental disorders. Setting WHO directions." Geneva: WHO.

Wondie, Y. et al. 2011. "Early marriage, rape, child prostitution, and related factors determining the psychosocial effects severity of child sexual abuse in Ethiopia," J Child Sex Abuse (3): 305-21.

World Bank. 2014. Country Data. http://data.worldbank.org/country/ethiopia.

Yizengaw, S. and A. Gebiresilus. 2014. "Triggering factors, risky behaviors and resilience of street children in Gondar city, North West Ethiopia," Innovare Journal of Social Sciences 2(4): 42-50. 

U.S. Agency for International Development I 300 Pennsylvania Avenue, NW

Washington, DC 20523

Tel: (202) 7I2-0000

Fax: (202) 216-3524

www.usaid.gov 